\title{
La familia rural leonesa $y$ sus funciones
}

\author{
Por Prisciliano CORDERO DEL CASTILLO
}

\section{INTRODUCCION}

En los números 117,118 y 119 de esta misma revista, correspondientes a los meses de enero-marzo, abril-junio y julioseptiembre de 1975, respectivamente, bajo el título "Estructuras de la familia rural leonesa: Un sistema cultural llamado a desaparecer", presenté un estudio sobre las estructuras y funciones que han venido acompañando durante muchos años a la familia rural de León. Ahora, a petición de varios lectores y para ofrecer una visión de la realidad socio-familiar de nuestros días, voy a presentar un breve análisis de las funciones que aún sigue manteniendo la familia rural de esta provincia.

Para la realización del presente estudio me serví de un breve cuestionario, que fue aplicado a la misma muestra, 50 pueblos de las cuatro zonas geográficas naturales de la provincia, descrita en el artículo anteriormente citado. La muestra humana tuvo que ser nuevamente elegida, ya que la anterior había sido seleccionada para otros fines concretos y no servía para el análisis presente.

La muestra actual, en la programación estuvo formada por 60 hombres y 40 mujeres, pero, a la hora de la realización, dadas las muchas dificultades para conseguir la información necesaria del sector femenino, hubo de cambiarse por la que aparece en las siguientes tablas: 
EDAD DE LAS PERSONAS ENTREVISTADAS

\begin{tabular}{|c|c|c|}
\hline Relación de edad & N. Personas & Porcentaje \\
\hline 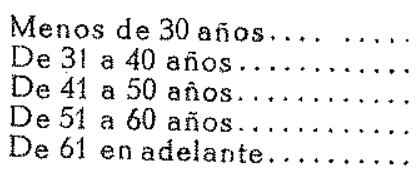 & $\begin{array}{r}3 \\
6 \\
33 \\
32 \\
6\end{array}$ & $\begin{array}{r}3,75 \\
7,50 \\
41,25 \\
40,00 \\
7,50\end{array}$ \\
\hline Total ............. & 80 & 100,00 \\
\hline
\end{tabular}

SEXO DE LAS PERSONAS ENTREVISTADAS

\begin{tabular}{|c|c|c|}
\hline$S \circ \times 0$ & Námero & Por eiento \\
\hline 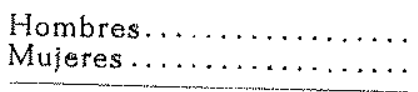 & $\begin{array}{l}65 \\
15\end{array}$ & $\begin{array}{l}81,25 \\
18,75\end{array}$ \\
\hline Total.............. & 80 & 100,00 \\
\hline
\end{tabular}

Considero necesario advertir que la muestra, aunque desde el punto de vista geográfico es representativa de toda la provincia, no consigue una representatividad numérica de la población, dado su reducido número de componentes, 80 personas en total, ante la población rural leonesa, que se puede calcular para nuestros días sobre las 400.000 personas. No obstante, el presente estudio siempre tendrá el valor de sondeo sociológico, realizado con todo rigor científico, y podrá servir para nuevas posibles investigaciones sobre cada uno de los campos aquí enumerados.

\section{FUNCIONES DE LA FAMILIA}

\section{La función biológica.}

La familia rural leonesa, que, al igual que las familias rurales de todo el mundo, se caracterizó por poseer un amplio número de hijos, hoy está siendo fuertemente influenciada por esa corriente universal de planificación familiar, impuesta por una serie de factores socio-económicos y culturales. No obstante, esta familia aún mantiene un índice de natalidad bastante superior al de la cludad. Concretamente, el 50 por 100 de los entrevistados tiene una media de tres o cuatro hijos, y un 22 por 100 tiene cinco hijos o más. 
Resulta interesante comparar el número de hijos que estas familias han tenido con el número de los mismos que, en caso de comenzar hoy su vida familiar, les gustaría tener. De hecho, mientras el 50 por 100 ha tenido de tres a cuatro hijos, hoy sólo al 39 por 100 le gustaría seguir teniendo este mismo número, y mientras un 17,50 por 100 tuvo dos hijos, hoy son el 31 por 100 de los entrevistados los que dicen querrían quedar en los dos hijos.

Se puede ver cómo la media de hijos deseados hoy está en dos o tres (el 49 por 100), mientras que la obtenida por estas mismas familias ha sido de tres o cuatro (el 50 por 100). La siguiente tabla compuesta nos ofrece una muestra clara de lo expuesto:

NUMERO DE HISOS TENIDOS Y LOS QUE OESEARIATENER HOY

\begin{tabular}{|c|c|c|c|c|}
\hline \multirow{2}{*}{ Hijos } & \multicolumn{2}{|c|}{ Hijos tenidos } & \multicolumn{2}{|c|}{ Hifos deseados hoy } \\
\hline & N. ${ }^{\circ}$ familias & Por ciento & N. familias & Por eiento \\
\hline 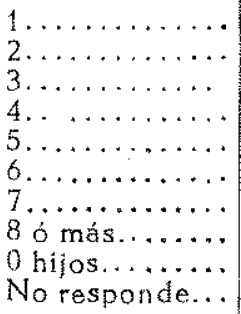 & $\begin{array}{r}4 \\
14 \\
20 \\
20 \\
9 \\
6 \\
1 \\
3 \\
0 \\
3 \\
\end{array}$ & $\begin{array}{r}5,00 \\
17,50 \\
25,00 \\
25,00 \\
11,25 \\
7,50 \\
1,25 \\
3,75 \\
0,00 \\
3,75\end{array}$ & $\begin{array}{r}4 \\
25 \\
14 \\
18 \\
5 \\
3 \\
0 \\
1 \\
2 \\
11\end{array}$ & $\begin{array}{r}5,00 \\
31,25 \\
17,50 \\
22,50 \\
6,25 \\
3,75 \\
0,00 \\
1,25 \\
2,50 \\
13,75\end{array}$ \\
\hline Total...... & 80 & 100,00 & 80 & 100,00 \\
\hline
\end{tabular}

Esta tabla ofrece algunos casos dignos de especial análisis. De las dos familias que hoy no desearian tener ningún hijo, una de ellas ha tenido dos, y la otra, tres. Se desconocen las razones que las han llevado a tales sentimientos. De las otras familias, aunque hubo cuatro que tuvieron sólo un hijo y hay otras cuatro que hoy desearian tener sólo uno, esto no quiere decir que se trate de las mismas familias. De hecho, sólo una de estas cuatro familias con un hijo desearía volver a tener un hijo solamente; de las otras, dos desearian tener dos hijos, y la otra, cuatro. A su vez, de los que hoy desean tener solamente un hijo, de hecho dos han tenido tres, y el otro, cuatro.

La única familia de la muestra que tuvo siete hijos hoy la gustaría tener sólo dos, y de las tres familias que tuvieron ocho, una desearía tener cinco; otra, tres, y la otra, dos solamente.

De los precedentes análisis se deduce que la tendencia a la reducción de los hijos o planificación familiar es común a 
casi la totalidad de la muestra. No obstante, existe un factor cultural que parece estar frenando la praxis del control en un alto porcentaje de familias, a juzgar por el 83,75 por 100 de la muestra, que admite la necesidad y obligación de aceptar todos los hijos que Dios le mande a uno.

La expresión "aceptar los hijos que Dios le mande", en el mundo cultural del campesino leonés es sinónima de “aceptar todos los hijos que la naturaleza dé de sí; por lo cual aparece una abierta contradicción entre una norma cultural de tipo reli. gioso, cada día menos practicada, pero que aún sigue siendo sentida como obligación, y una práctica o deseo de práctica.

\section{Función económica.}

La familia rural leonesa aún hoy sigue siendo unidad económica y centro de producción, pero se encuentra reducida a las mínimas dimensiones. Los hijos, las nuevas generaciones, no ven ya en la familia rural su futuro económico ni su sistema de vida. De esta forma, la familia rural se ha visto reducida en un alto porcentaje al matrimonio o, como mucho, al matrimonio y a un hijo. Por ejemplo, en el caso de la muestra estudiada, el 16 por 100 de las familias se han visto reducidas al padre o cabeza de familia como unidad de producción, y el 60 por 100, a dos unidades de trabajo, que muchas veces están formadas por el padre y la madre.

En cuanto al tiempo o número de horas empleadas en el trabajo a la semana, es difícil de concretar, dada la diversidad de las jornadas laborales en las distintas épocas del año y en las distintas zonas geográficas. No obstante, el campesino tiene conciencia de trabajar más horas que en cualquier puesto de trabajo de la ciudad. Así, el 26 por 100 de los entrevistados dice trabajar de 41 a 50 horas a la semana; el 16,25 por 100 , de 51 a 60 horas, y el 28,75 por 100 , más de 61 horas. Es decir, hay conciencia de superocupación o pluriempleo, aunque sea siempre dentro del mismo trabajo familiar agrícola o ganadero, con el agravante de que existe también una conciencia clara de la falta de rentabilidad de este trabajo, como lo confiesa el 65 por 100 de la muestra. A pesar de todo, el 81,25 por 100 dice que se vive mejor en el campo que en la ciudad.

¿Son sinceros los campesinos al dar esta respuesta o, por el contrario, usan este recurso como argumento defensivo ante sí mismos y ante los demás para justificar su falta de decisión y valentía para dejar el campo, acusación que ellos mismos muchas veces se hacen? Si es cierto que piensan que vive mejor el hombre del campo que el de la ciudad, ¿por qué, a la hora de pensar en la estratificación de sus hijos, el 100 por 100 
de los entrevistados habla de profesiones totalmente ajenas al campo?

Aunque la tradición popular leonesa ha presentado a la mujer como administradora de la economía doméstica, en el presente sondeo aparece el hombre, el marido, como el principal administrador de todos los bienes de la familia en un porcentaje muy superior al de la mujer (el 66,25 por 100). No obstante, en un 85 por 100 de veces consulta con su mujer para cualquier tipo de operación administrativa.

\section{Función protectora.}

Muchos de los cambios que se han registrado en la familia urbana están apareciendo actualmente en la familia rural y hacen que esquemas y modelos de un sistema familiar patriarcal cedan el paso a nuevas formas democráticas y de autoridad compartida, según se deduce de la muestra, en la que el 65,2 por 100 se manifiesta partidario de que la autoridad de la familia sea compartida por el marido y la mujer, y el 77,5 por 100 condena que el padre tome decisiones de tipo familiar sin contar con su esposa. Sin embargo, cuando se pregunta si la madre puede tomar decisiones familiares sin contar con su marido, la respuesta negativa es aún más global, llegando a alcanzar hasta el 90 por 100 de la muestra.

Aunque el padre de familia ha accedido a compartir la autoridad familiar con su mujer en un gran porcentaje, no sucede lo mismo cuando se trata de sus hijos, a quienes quisiera tener totalmente sometidos hasta que contrajesen matrimonio en un 58,7 por 100 de casos, o, al menos, hasta los veintiún-veintícinco años en un 25 por 100 de casos y a quienes quisiera controlar sus acciones o pedir cuenta de ellas en un 98,75 por 100 .

Se puede hablar, pues, de una pérdida relativa de la función protectora de la familia y de un cambio más sustancial en el modo de ejercer la autoridad, aunque no se haya llegado al sis. tema democrático e ideal de la familia moderna.

\section{Función cultural.}

Aspirando, como la inmensa mayoría de los padres campe. sinos aspiran, a que sus hijos se sitúen fuera del mundo rural, en puestos de trabajo que exigen una especialización y, por consiguiente, una preparación técnica, es obvio que aquella cultura tradicional, transmitida de generación en generación, sirve de muy poco a la hora de pensar en la estratificación de los hijos. 
Este cambio de tipo socio-económico ha hecho que el papel de transmisor de una cultura, tradición y costumbres, que tuvo el padre de familia rural leonesa, hoy sea muy reducido y de escasa importancia, dado su bajo grado de educación formal.

Aunque el analfabetismo es bastante reducido en toda la provincia, exactamente el 7,5 por 100 entre los hombres y el 6,2 por 100 entre las mujeres, sin embargo, existe un 17,5 por 100 de hombres y otro 16,2 de mujeres que sólo asistieron de uno a cinco años a la escuela, no habiendo finalizado los estudios primarios y, por consiguiente, careciendo aún de este grado de educación que conferían las escuelas rurales. Incluso de aquel 60,5 por 100 que cursaron todos los estudios primarios son muy pocos los que han mantenido la costumbre de leer y formarse. No obstante, la totalidad de los entrevistados reconoce la importancia de la educación y el 78,5 por 100 desearía que sus hijos llegasen a cursar estudios universitarios.

Esta es la gran aportación que la familia rural leonesa está haciendo, en el plano cultural, a las nuevas generaciones: estimularlas y proporcionarlas una base cultural y educacional que las generaciones anteriores no pudieron conseguir.

El padre de familia, además del estímulo y apoyo que infunde en sus hijos por una educación superior, intenta también influir en ellos transmitiéndoles una serie de costumbres, formas sociales y valores y una serie de creencias y prácticas religiosas, exigidas con más o menos rigor.

Aunque la exigencia de las prácticas religiosas es cada vez menos impuesta por la autoridad familiar sobre sus hijos, la intolerancia sería casi absoluta-el 81,25 por 100 -si se tratase de pasar de la religión católica a otras religiones.

\section{Función estratificativa.}

La familia rural sigue teniendo conciencia de su función estratificativa, de tal manera que el 75 por 100 de la muestra se cree con la obligación de dar una profesión a sus hijos; pero sabe que esa profesión la tendrá que buscar fuera del ambiente familiar. Este es el gran cambio que se ha experimentado en la familia rural actual, comparada con la de hace unas décadas. que daba un status a sus hijos en su mismo ambiente.

Es elocuente constatar que de entre las profesiones deseadas para sus hijos, ninguno de los entrevistados menciona la de agricultor o ganadero: 
PROFESIONES DESEADAS

\begin{tabular}{|c|c|c|}
\hline Relasión & $N^{\circ}$ faml. & Por clento \\
\hline $\begin{array}{l}\text { Trabajos profesionales a liberales } \ldots \ldots \ldots \\
\text { Lo que ellos quieran } \ldots \ldots \ldots \ldots \ldots \ldots \ldots \\
\text { Que dejen el campo } \ldots \ldots \ldots \ldots \ldots \ldots \ldots \ldots \\
\text { lndustriales } \ldots \ldots \ldots \ldots \ldots \ldots \ldots \ldots \ldots \\
\text { No responden } \ldots \ldots \ldots \ldots \ldots \ldots \ldots \ldots\end{array}$ & $\begin{array}{r}38 \\
20 \\
4 \\
4 \\
14\end{array}$ & $\begin{array}{r}47,50 \\
25,00 \\
5,00 \\
5,00 \\
17,50 \\
\end{array}$ \\
\hline 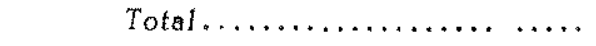 & 80 & 100,00 \\
\hline
\end{tabular}

Es interesante, pero a la vez desolador, ver cómo todos estos hombres, a la hora de pensar en el futuro de sus hijos, prefieren que tengan una profesión cualquiera, que sean lo que ellos quieran, pero, a ser posible y mayoritariamente, quieren verles fuera del campo, lejos de todo lo que es más querido y forma parte de su misma personalidad: las tierras, los ganados, los pastos, los valles y colinas, en donde ellos y sus mayores llegaron a echar raíces.

Este dato es el mayor grito de protesta de toda una población marginada que, con este gesto de dolorosa resignación, condena la forma en que se ha visto tratada y busca para los suyos algo distinto, aunque tenga que ser en ambientes lejanos y desconocidos.

\section{Función afectiva.}

Se considera la función afectiva, relaciones personales entre esposos, entre padres e hijos y entre hermanos, como la función típica y característica de la familia moderna, que se manifiesta en una forma concreta de trato entre los distintos miem. bros de la familia.

Así como hemos visto qué modelos de conducta de la familia rural han pasado a la familia urbana, asi también la función afectiva, caracteristica de la familia moderna, está imponiéndose como pauta de conducta en la familia rural. Aquel trato de "Ud.", por ejemplo, obligatorio para todos los hijos al hablar con sus padres y característico de todo el mundo rural leonés, hoy ha quedado reducido al 33 por 100 de las familias, y son ya el 66,5 por 100 de los padres de las familias rurales los que consienten que sus hijos les traten de "tú". Asimismo, el 73,75 por 100 de los entrevistados dice hacer partícipes a sus hijos de los problemas familiares y dialogar con ellos sobre todos los asuntos de la casa. Igualmente, se están imponiendo en la familia rural formas de conducta que dejan entrever un enriquecimiento 
en las relaciones afectivas entre esposos, padres e hijos, como son las celebraciones de los "santos" o cumpleaños, que los celebran un 70 por 100 de las familias, el intercambio de regalos con estas y otras ocasiones, que se hace en un 66,5 por 100 de los hogares, etc.

Aunque estas notas positivas hacen crear ciertas esperanzas en la familia rural leonesa, sin embargo, aparecen con frecuencia otras que nos recuerdan insistentemente el alto grado de insatisfacción existente en el mundo rural, que está afectando a las generaciones jóvenes e incluso dañando a la misma función afectiva.

Tomando como base, para el análisis de la integración de las nuevas generaciones en el mundo rural, el fenómeno psicoló. gico de la imitación en los juegos, vemos cómo el niño rural leonés sólo imita a sus padres y a las profesiones de éstos en un 35 por 100 , mientras que el 52,5 por 100 prefiere imitar en sus juegos a personas del mundo urbano y de la sociedad de consumo, propuestas por los medios de comunicación social. Este hecho manifiesta una clara falta de armonía y compenetración afectiva entre el niño y sus padres. El niño, con la elec. ción de modelos para sus juegos, nos está diciendo que ya ha visto la diferencia entre las personas de su padre o madre, cansados, desaliñados y sudorosos, debido a la clase de trabajo que les ocupa, y esas otras personas, envueltas en una aureola de publicidad, juventud y felicidad, que ven en la televisión, por ejemplo.

Esta puede ser la primera frustración que le produce la realidad rural, al conocer esas otras clases sociales distintas y superiores a la suya.

La insistente aparición de la falta de confianza en sí mismos y en los demás, de una creciente desilusión por la vida del campo y de una falta de visión de futuro para la familia rural y, en definitiva, para la misma sociedad campesina, me hace terminar lanzando un S.O.S., esperando que haya alguien que lo recoja y acuda con urgencia a la llamada para luchar por instaurar unas nuevas estructuras económicas, demográficas y sociales, que permitan una desarrollo armónico de estas tierras, de sus gentes y de su sistema cultural y familiar. 